\title{
Cardiovascular MR angiography in partial anomalous pulmonary venous connection
}

\author{
Jan Menke
}

Institute for Diagnostic and Interventional Radiology, University Medical Center Goettingen, Goettingen, Germany

\section{Correspondence to} Dr Jan Menke, Menke-J@T-Online.de

Accepted 14 February 2015

\section{DESCRIPTION}

A 17-year-old girl was assessed for exercise-induced hypertension. Her medical and family history were unremarkable. After fast running during school sport she had felt unwell with headache for about an hour. Subsequently, she presented to her paediatrician who measured elevated blood pressures and decided on further diagnostic work up. The $24 \mathrm{~h}$ blood pressure measurements were normal, but bicycle ergometry was stopped when the patient reached a high systolic/diastolic blood pressure of $256 / 96 \mathrm{~mm} \mathrm{Hg}$ at $2.4 \mathrm{~W} / \mathrm{kg}$. Chest radiography and subsequent MRI showed an aberrant right pulmonary vein (an infracardiac type of partial anomalous pulmonary venous connection), whereas the lung was normal (no Scimitar syndrome). At that time the patient's symptoms were minor, and she and her parents decided against diagnostic/interventional catheter angiography.

Ten years later the patient opted for further diagnostics since she now had exercise-induced dyspnoea. A temporally resolved contrast-enhanced cardiovascular MR angiography was performed. According to phase contrast imaging, the pulmonary-to-systemic flow ratio was elevated to 1.4-to-1, indicating left-to-right shunting. On the right side several small lung veins drained into an abnormal vertical vein (figure $1 \mathrm{~A}$, arrows) with anomalous venous return into the inferior vena cava (figure $1 \mathrm{~A}, \mathrm{~B},{ }^{*}$ ). Two right pulmonary veins drained independently into the left atrium, whereas two other tortuous right pulmonary veins extended from the left atrium to the vertical vein (figure $1 \mathrm{~B}$, arrowheads; online supplementary figure S2; video 1). Effectively, this represented dual drainage from the vertical vein into

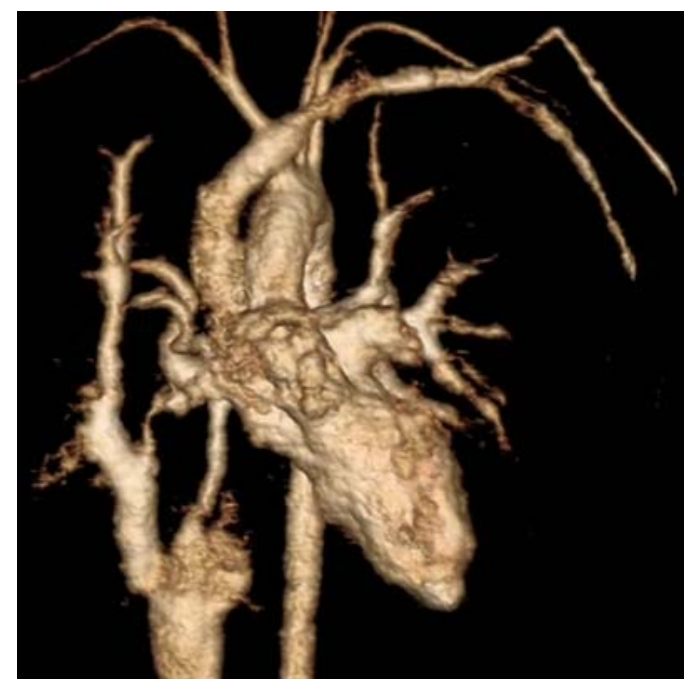

Video 1 Cardiovascular MR angiography, rotating volume rendering. A time-resolved three-dimensional MR angiography was performed using a dynamic TWIST (time-resolved angiography with interleaved stochastic trajectories) sequence during intravenous injection of gadolinium chelates. The rotating volume rendering was produced after subtracting a pulmonary arterial contrast phase from a systemic arterial contrast phase. In this way the right atrium, right ventricle and the pulmonary arteries are excluded. The video showing normal anatomy of the left pulmonary veins. On the right side a large abnormal pulmonary vertical vein is connected to the inferior vena cava. Two of four right pulmonary veins drain independently into the left atrium. Two other tortuous right pulmonary veins extend from the left atrium to the vertical vein.

the inferior vena cava and into the left atrium. This vascular anatomy allowed for interventional occlusion of the distal vertical vein by an Amplatzer

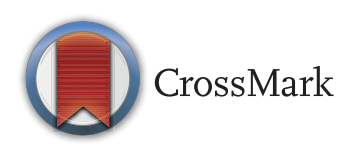

To cite: Menke J. BMJ Case Rep Published online: [please include Day Month Year] doi:10.1136/bcr-2014208678
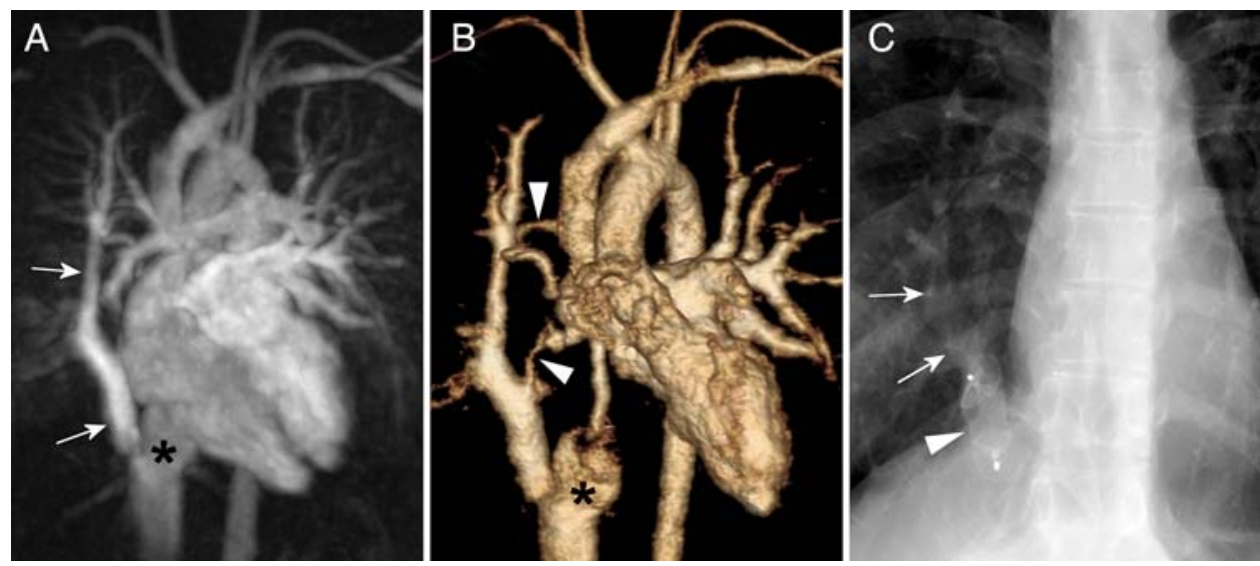

Figure 1 (A) Maximum intensity projection of the MR angiography (MRA). (B) Volume rendering of the MRA. The right atrium, right ventricle and the pulmonary arteries were excluded by subtracting the pulmonary arterial phase from the systemic arterial phase. A rotating volume rendering is supplied in video 1. (C) Chest radiography after occlusion of the distal vertical vein by a vascular plug. See full text for the description of the figure symbols ("* " arrows, and arrowheads). 
vascular plug (figure $1 \mathrm{C}$, arrowhead) ${ }^{1}$ by paediatric cardiologists after a balloon occlusion test had been successful. Subsequently, the patient was well and without dyspnoea.

In general, the indication for surgical or interventional treatment versus conservative treatment in partial anomalous pulmonary venous connection depends on individual factors, such as a patient's symptoms. ${ }^{1}{ }^{2}$ Cardiovascular MR angiography is useful for non-invasive assessment of the associated left-to-right shunting

\section{Learning points}

- In partial anomalous pulmonary venous connection some but not all pulmonary veins of the left or right lung recircle oxygenated blood towards the right of the heart.

- Cardiovascular MR angiography can measure the associated left-to-right shunting and can depict the anomalous vasculature three-dimensionally.

- The clinical decision for surgical/interventional versus conservative treatment depends on individual factors, including a patient's symptoms. and for depicting the anomalous pulmonary vasculature threedimensionally. ${ }^{2} 3$ Similar cases may be recognised, particularly by exercise-induced dyspnoea, where conditions with left-to-right shunting and subsequently increased right ventricular output are among the several differential diagnoses. Chest X-ray may give a hint when the aberrant vein is identified as a well-demarcated vertical shadowing (normally all pulmonary vessels are directed towards the central hilus).

Competing interests None.

Patient consent Obtained.

Provenance and peer review Not commissioned; externally peer reviewed.

\section{REFERENCES}

1 Baspinar O, Irdem A, Kilinc M. Transcatheter repair of partial anomalous pulmonary venous drainage using an amplatzer vascular plug in a postoperative patient with tetralogy of Fallot. Pediatr Cardiol 2013;34:1041-3.

2 Fragata J, Magalhaes $M$, Baquero L, et al. Partial anomalous pulmonary venous connections: surgical management. World J Pediatr Congenit Heart Surg 2013:4:44-9.

3 Robinson BL, Kwong RY, Varma PK, et al. Magnetic resonance imaging of complex partial anomalous pulmonary venous return in adults. Circulation 2014;129:e1-2.

Copyright 2015 BMJ Publishing Group. All rights reserved. For permission to reuse any of this content visit http://group.bmj.com/group/rights-licensing/permissions.

BMJ Case Report Fellows may re-use this article for personal use and teaching without any further permission.

Become a Fellow of BMJ Case Reports today and you can:

- Submit as many cases as you like

- Enjoy fast sympathetic peer review and rapid publication of accepted articles

- Access all the published articles

- Re-use any of the published material for personal use and teaching without further permission

For information on Institutional Fellowships contact consortiasales@bmjgroup.com

Visit casereports.bmj.com for more articles like this and to become a Fellow 